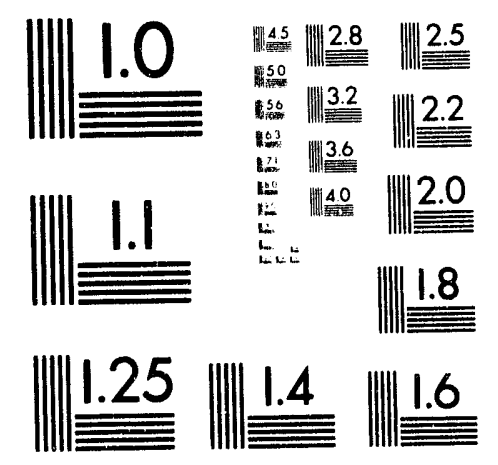



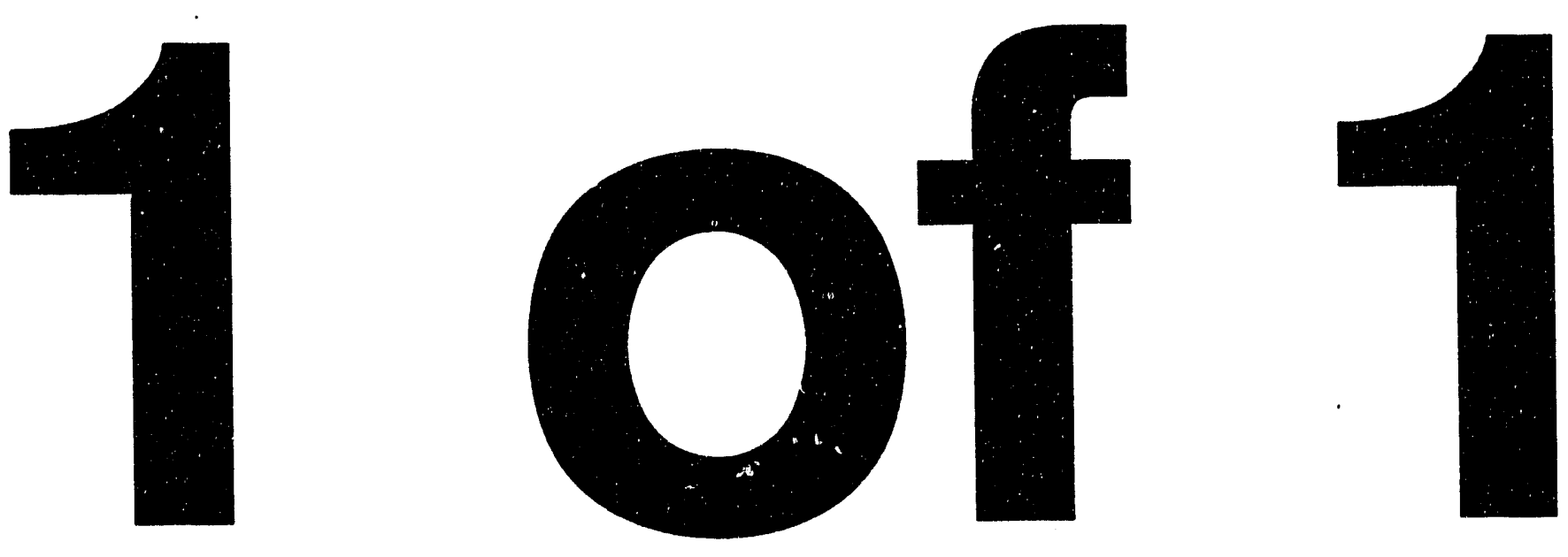


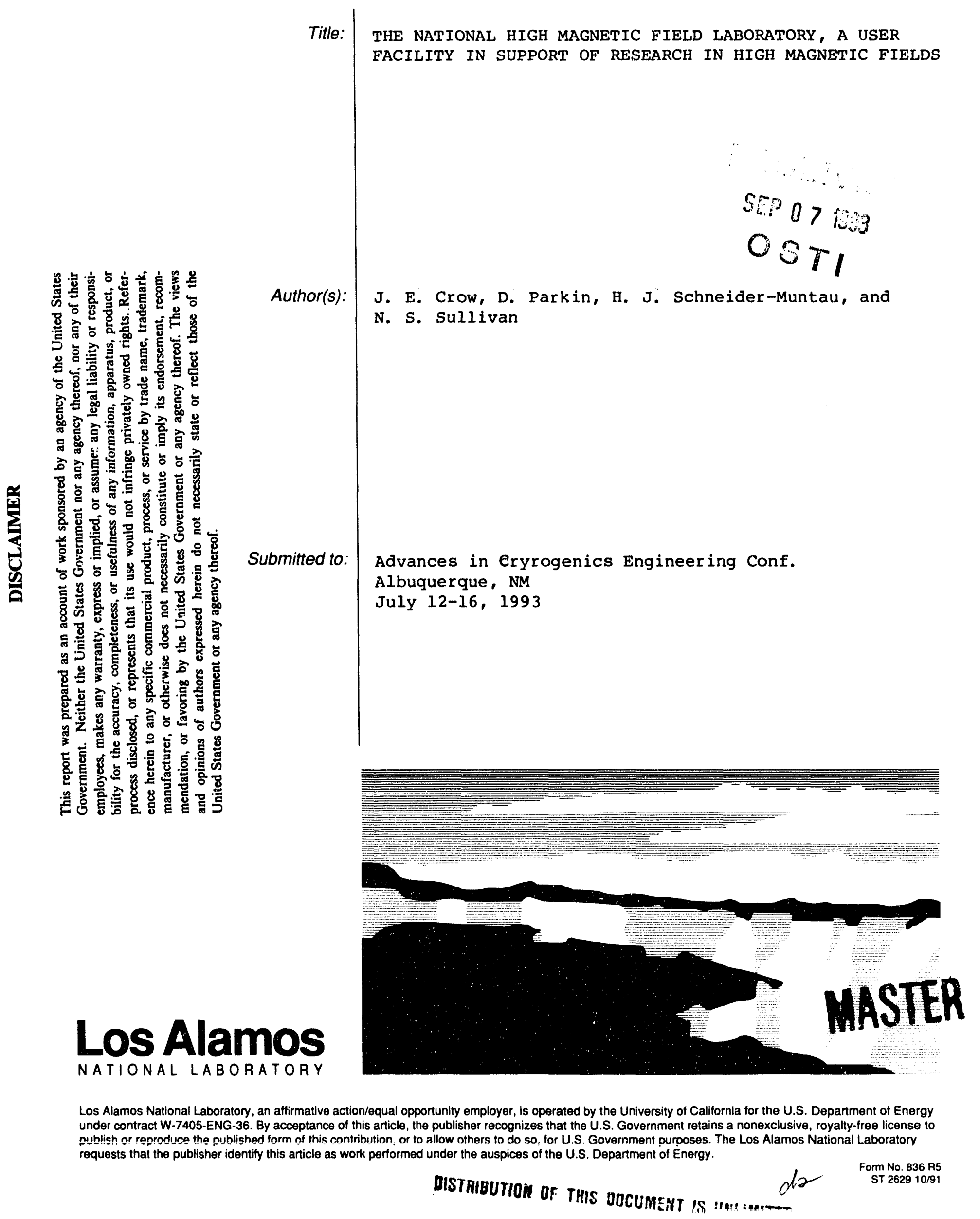




\title{
THE NATIONAL HIGH MAGNETIC FIELD LABORATORY, A USER FACILITY IN SUPPORT OF RESEARCH IN HIGH MAGNETIC FIELDS
}

\author{
J.E. Crow, ${ }^{1}$ D. Parkin, ${ }^{2}$ H.J. Schneider-Muntau, ${ }^{1}$ and N.S. Sullivan 3

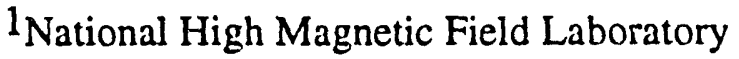 \\ Florida State University \\ Tallahassee, FL 32306 \\ ${ }^{2}$ Center for Materials Science \\ Los Alamos National Laboratory \\ Los Alamos, NM 87545 \\ ${ }^{3}$ Department of Physics \\ $\therefore \quad$ University of Florida \\ Gainesville, FL 32611
}

\begin{abstract}
The National High Magnetic Field Laboratory (NHMFL) develops and operates high magnetic field facilities at its main location at Florida State University, Tallahassee, as well as a pulsed magnetic field facility at Los Alamos National Laboratory. A number of specialized facilities are also available to collaborators at the University of Florida for research at ultra-low temperatures, advanced magnetic resonance imaging, and materials sciences. The NHMFL is supported by the United States National Science Foundation (NSF) and by the State of Florida. It is a user facility available to qualified users through a peer review proposal process. The facilities and staff support research and development at the extremes of parameter space. A part of its activities is devoted to the advancement of the state of the art of superconducting, pulsed, resistive, and $t_{i j}$ brid magnets. This involves cryogenic materials research, the development of high strength, high conductivity conductors, and the development of low and ultra low temperature systems.
\end{abstract}

\section{INTRODUCTION}

The National High Magnetic Field Laboratory (NHMFL) was founded in August 1990. Jointly funded by the United States National Science Foundation and the State of Florida, this laboratory will be operated by a consortium composed of Florida State University (FSU) in Tallahasse, the University of Florida (UF) in Gainesville, and the Los Alamos National Laboratory (LANL) in Los Alamos, New Mexico. This laboratory will be a major magnetic field facility in the United States.

The charter of the laboratory foresees the development of continuous and pulsed magnetic field systems along with the corresponding research infrastructure. It is the mission of the 
laboratory to establish a state-of-the-art high magnetic field facility driven by an internationally competitive in-house research and development program, while also being responsive to the needs of the user community. A new progressive generation of magnets has to be built in order to advance magnet related research at the highest attainable fields in biology, tiomedical areas, chemistry, geology, physics, and materials science.

The facilities in Tallahassee, Florida house the resistive, superconducting, and hybrid magnets which generate continuous magnetic fields. This facility will also include the Institute for Advanced Studies in Magnetic Resonance, dedicated to research in the fields of magnetic resonance imaging, high-field high-resolution NMR, ion cyclotron resonance, and electron spin resonance. These goals can only be achieved at such a laboratory as the NHMFL, where the development of new technologies and high field capabilities can be carried out to their maximum potential.

In addition to those facilities being developed at FSU, the NHMFL will support a specially designed magnet system along with a demagnetization cryostat at the Microkelvin Research Laboratory located at the University of Florida in Gainesville. This facility provides collaborative research opportunities for studies at the highest ratios of $B / T$ and in ultra-quiet environments. Part of the MRI research efforts will be pursued in cooperation with the UF Brain Institute, also located on the university campus. The theory group at the University of Florida, as well as the materials and condensed matter activities, are coordinated with those at the NHMFL.

The pulsed field facilities are located at LANL in Los Alamos, New Mexico. A capacitive driven pulsed field user facility has been established, where magnetic field pulses of 50 and 60 $T$ are available on a routine basis. A new system, capable of generating $60 \mathrm{~T}$ in a bore of $32 \mathrm{~mm}$ with a flat top of at least $100 \mathrm{~ms}$ is being designed and built. There is also an explosively driven flux compression facility capable of supporting research at the highest fields. The progress of these facilities is supported by the NHMFL magnet development group and materials research and processing groups. The engineering of new magnet systems depends crucially on the development and characterization of new conducting materials with high strength.

This new laboratory, as introduced above, is operated as a user facility, open to qualified researchers both nationally and internationally. Users will be granted access to the facilities of the NHMFL through a proposal process with peer review. There will be a graded approach to the review of these proposals. The initial visit will be approved by the Director in consultation with the Associate Directors, in-house researchers, or members of the Users' Committee. This process will allow quick access for new experiments. Continued use of the facilities will require approval by two reviewers who are on a list of reviewers approved by the NSF and the NHMFL External Advisory Committee.

This paper describes the main facilities which are being developed within the NHMFL and their present status.

\section{NHMFL AT TALLAHASSEE, FL}

\section{Buildings}

The NHMFL at Tallahassee houses the DC facilities and all those facilities necessary to support and maintain the development, fabrication, installation, and repair of the continuous 


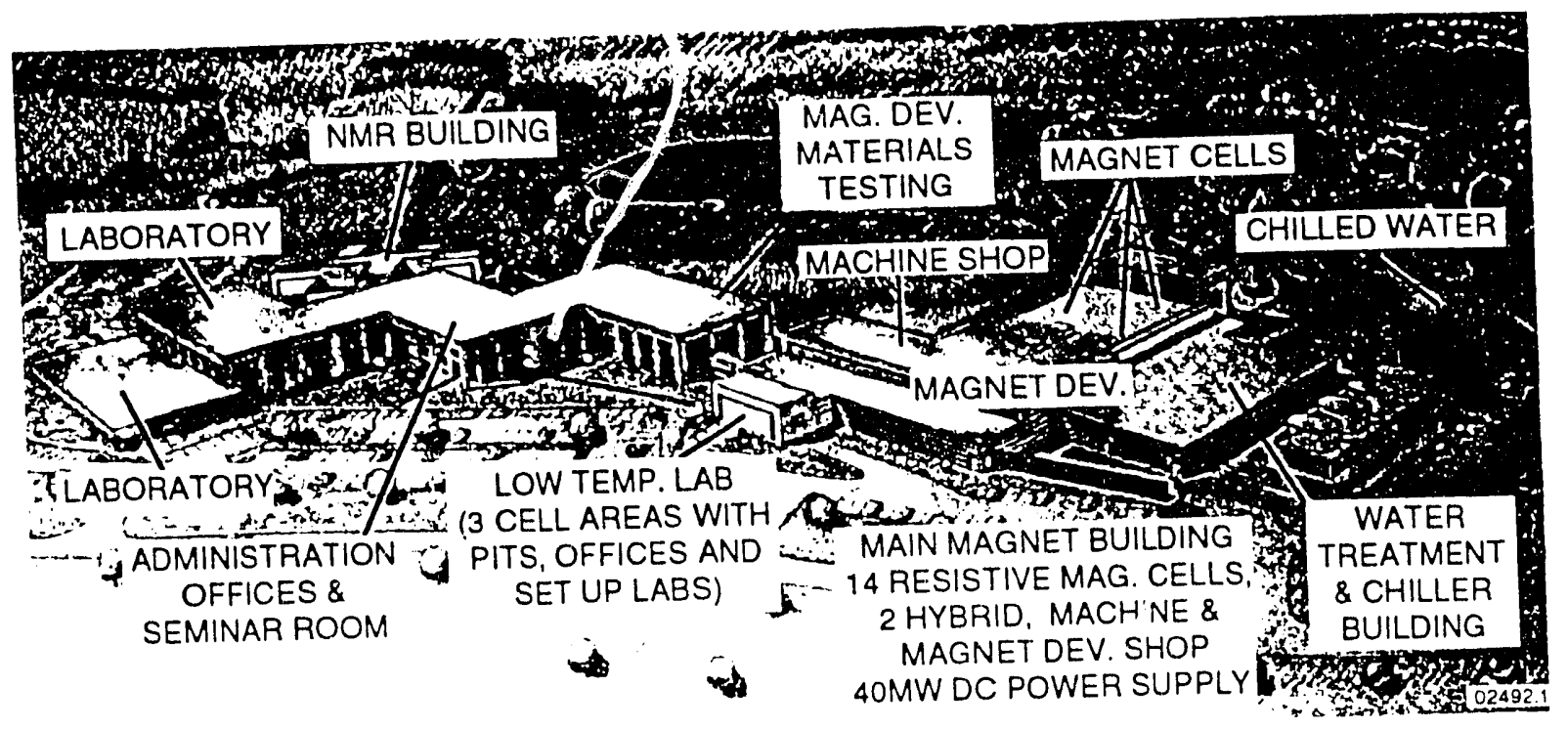

Figure 1. Architectural sketch of the NHMFL at Florida State Universtiy, Tallahassee, FL.

magnets and some pulsed field magnets. Most of the facilities supporting the development of the in-house science and technology progras are also located here.

The facility for the resistive magnets (Main Magnet Building on figure 1, about $7,500 \mathrm{~m}^{2}$ ) consists of 14 resistive magnet cells, each roughly $5 \mathrm{~m}$ wide, $12 \mathrm{~m}$ long, and $10 \mathrm{~m}$ high, two hybrid cells of $14 \mathrm{~m} \times 12 \mathrm{~m} \times 15 \mathrm{~m}$, and all the space required to house the power supplies, cooling circuits, and the power and cooling water distribution. This building also contains the support facilities, including the machine and electronics shops and a magnet development shop with a clean room for magnet assembly and testing. The magnet development program is supported by a materials development and characterization program which includes material processing equipment, i.e. wire drawing benches and heat treatment furnaces, along with laboratories to characterize these materials. Two hydraulic tensile testers have been installed recently. A metallography and electron microscopy laboratory is being constructed and will be equipped with state-of the art instruments.

Attached to the main building are two additional facilities specifically built to house, in an optimum way, highly specialized research experiments; there is a dedicated milli-Kelvin research area with three $5 \mathrm{~m}$ deep pits and the NMR laboratory (see Figure 1). To reduce any interference between the NMR and ICR systems and the environment, the building was added on the far most end of the complex, designed with widely separated research pods, and is constructed chiefly of non-ferromagnetic materials. The building has a surface area of almost $3,000 \mathrm{~m}^{2}$, which includes preparation labs and other necessary infrastructure.

The main building (about 16,000 $\mathrm{n}^{2}$ ) allocates a large fraction of space to support general sciences. It houses a great number of research laboratories of all sizes, partly equipped with exhaust hoods. Also, for experimental set-ups that require sufficient overhead space, there are 4 large high bay area laboratories.

The wing adjacent to the Main Magnet Building is reserved for superconducting ritagnet and cryogenic development. The first floor houses the magnet development and technology group. Part of the second floor is occupied by administration, technical, and publication services. The theory group occupies the third floor. The central part of the building houses the Director's office and the offices of his support staff, also the library, seminar room for about 150 persons, and laboratories. 
Table 1. The NHMFL Power Supply and Cooling Circuit

- Performance Requirements

Ripple and noise $(0-500 \mathrm{~Hz})$ :

Stability including ripple:

$10 \mathrm{ppm}$

Repeatability including ripple:

Resolution between adjacent steps:

$100 \mathrm{ppm}$

$100 \mathrm{ppm}$

$10 \mathrm{ppm}$

Accuracy (current calibration):

$1000 \mathrm{ppm}$

- Power Ratings

$\begin{array}{llll}\begin{array}{l}\text { Nominal rating } \\ \text { Voltage }\end{array} & 24 \mathrm{MW} & 32 \mathrm{MW} & 40 \mathrm{MW} \\ \begin{array}{l}\text { Current } \\ \text { Maximum }\end{array} & 400 \mathrm{~V} & 500 \mathrm{~V} & 500 \mathrm{~V} \\ \begin{array}{l}17 \mathrm{KA} \\ \text { rating }\end{array} & 17 \mathrm{kA} & 20 \mathrm{kA} \\ & \begin{array}{l}4 \times 6.8 \mathrm{MW} \\ 27.2 \mathrm{MW}\end{array} & \begin{array}{l}4 \times 8.5 \mathrm{MW} \\ 34 \mathrm{MW}\end{array} & \begin{array}{l}4 \times 10 \mathrm{MW} \\ \end{array} \\ \begin{array}{l}\text { Maximum } \\ \text { operating time }\end{array} & \text { infinite } & 12 \text { hours } & 1 \text { hour }\end{array}$

- Cooling Circuit

4 pumps, each 30 bars, $100 \mathrm{Vs}$

4 chillers, each $7 \mathrm{MW}$, storage tank $3.8 \cdot 103 \mathrm{~m} 3=56 \mathrm{MWh}$

$7^{\circ} \mathrm{C}, 10 \mathrm{M} \Omega \mathrm{cm}$, gas free, low vibration level

The left, and largest part, of the building is dedicated entirely to the experimental sciences. It houses the majority of laboratories and offices for researchers.

The Main Magnet Building is presently available and a limited user operation has already begun. All other building projects will be completed by September 1993. The official dedication ceremony is planned to take place in November 1993.

\section{Technical Installations}

DC Power Supply. Located in the Main Magnet Building is the DC power supply for the resistive magnets. It consists of four identical units with a total nominal rating of 24 or $32 \mathrm{MW}$. These two levels can be set by changing the nominal operation voltage from 400 to $500 \mathrm{~V}$.

The nominal current is $17 \mathrm{kA}$ per power supply, therefore, the maximum ratings are 27 and $34 \mathrm{MW}$ (see table 1). The power supplies can be run in an overload mode up to $20 \mathrm{kA}$, and are then limited by the available thermal heat capacity of the water cooled transformers and chokes. It is assumed that an operating time of one hour at the full power level of $40 \mathrm{MW}$ will be possible. To increase reliability, the thyristors are only run at $50 \%$ of their maximum rating. This means that the power supply could be used to give DC pulses of up to $68 \mathrm{MW}$. This choice of voltage and current ratings was chosen in order to be compatible with most other magnet laboratories. The four units can be run individually or coupled in parallel galvanically or magnetically. Each unit is a 24 pulse thyristor bridge type rectifying unit. A passive filter (LC circuit) and an active filter, consisting of an in series transistor amplifier, reduces ripple and noise to the required values as listed in Table 1. A high precision zero-flux current transformer is used as the current measuring device. 
The power supplies are actually being tested with a $10 \mathrm{MW}$ resistive load.

Cooling Water System. The cooling water system for the facility was designed to provide the necessary cooling for the resistive magnets, the power supply, and the central air conditioning system. The actual system was designed to accommodate a continuous load of 28 $\mathrm{MW}$, the cooling capacity of 4 chillers. There is space to add a fifth chiller, if future requirements show it to be necessary. For peak loads and smooth operation of the chillers, a storage tank of $3800 \mathrm{~m}^{3}$ was added. This allows the system to run at a maximum load of $32 \mathrm{MW}$ for about 12 hours (see Table 1). The water temperature of this cooling circuit is kept at a constant temperature of $5{ }^{\circ} \mathrm{C}$. Evaporative cooling towers are used for heat rejection of the chillers. The innermost water circuit uses deionized water for the cooling of the resistive magnets. A specially designed water treatment system assures high resistivity (at least 10 $\mathrm{M} \Omega \mathrm{cm}$ ) and very low dissolved gas levels. Four variable speed pumps with a maximum rating of $100 \mathrm{~L} / \mathrm{s}$ at 4.0 bars each supply the cooling water to the magnets. With the help of regulation valves, the iniet temperature of the magnets will be kept at a constant water temperature of 7 ${ }^{\circ} \mathrm{C}$. The pump speeds can be regulated to satisfy special demands of magnets concerning pressure drop or flow rate. Special attention was paid to assure very low vibration levels in the hydraulic system. Pumps and part of the tubing are suspended by vibration dampers, with other parts fixed rigidly to the floor, a heavy mass of 6000 tons of concrete.

A sophisticattd, commercial, state-of-the-art computer control system assures correct and failure free operation of this complex equipment. It also monitors and stores critical data such as the resistance of magnets, consumption, running time of components etc., i.e., long time behavior and short time fluctuations of all critical parameters.

The technical installations are actually in the test and acceptance phase.

Table 2. Resistive Magnet Program of the NHMFL

\begin{tabular}{llll}
\hline $\begin{array}{l}\text { Power } \\
(\mathbf{M W})\end{array}$ & $\begin{array}{l}\text { Bore } \\
(\mathbf{m m})\end{array}$ & $\begin{array}{l}\text { Field } \\
(\mathbf{T})\end{array}$ & $\begin{array}{l}\text { Coils } \\
\text { (No) }\end{array}$ \\
\hline $8.5^{*}$ & 50 & 20 & 2 \\
$12.8^{*}$ & 32 & 27 & 3 \\
$12.8^{*}$ & 50 & 25 & 3 \\
$13.6^{*}$ & 32 & 30 & 7 \\
$13.6^{*}$ & 50 & 27 & 6 \\
& & & \\
$24^{*}$ & 32 & 32 & 5 \\
24 & 50 & 30 & 5 \\
24 & 32 & 35 & 11 \\
24 & 50 & 33 & 10 \\
25 & 200 & 21 & 3 \\
& & & 5 \\
32 & 32 & 35 & 5 \\
32 & 50 & 33 & 11 \\
32 & 32 & 38 & 10 \\
32 & 50 & 35 & 11 \\
\hline
\end{tabular}

*These magnet systems will be available by the end of 1994. 
Magnet Systems. The magnet systems to be developed and installed in the NHMFL include resistive, superconducting, and hybrid magnets. In addition, there will be magnets designed and dedicated to specific tasks, e.g., magnet systems for high resolution NMR spectrometers, Fourier transform ion cyclotron resonance mass spectrometry, and high field, small animal NMR imaging magnets. The resistive magnet design under consideration includes Bitter, poly-Bitter, and poly-helix configurations. Table 2 gives a list of the planned resistive magnet development program. The magnets at the three main power levels (10$14 \mathrm{MW}, 24 \mathrm{MW}$, and 32-40 MW) are designed as large bore, reliable Bitter magnets with plugin units, which can be easily replaced. These plug-in units are either lower field Bitter magnets, or high field multi-coil poly-Bitter or poly-helix coils for two different bore diameters, i.e., 32 and $50 \mathrm{~mm}$ room temperature bores. In autumn of this year, three magnet sites will be available. The magnet housings will be equipped with $20 \mathrm{~T}, 50 \mathrm{~mm}$ bore coils which were built in cooperation with the High Field Magnet Laboratory in Grenoble. One of these inserts will be replaced at the end of this year by the first magnet designed and built at the NHMFL, a $27 \mathrm{~T}$, $32 \mathrm{~mm}$ system. In the beginning of 1994 three additional $12 \mathrm{MW}$ sites will be installed and also a $25 \mathrm{~T}, 50 \mathrm{~mm}$ bore system will be available. One of these inner coils will be replaced by a polyBitter insert in the autumn of 1994 , designed to give at least $30 \mathrm{~T}$. The first $24 \mathrm{MW}$ site will be installed by the end of 1994 and house a 32 T, $32 \mathrm{~mm}$ magnet.

In a joint funding effort the NHMFL and the Francis Bitter National Magnet Laboratory are developing a $45 \mathrm{~T}$ hybrid magnet. It consists of a $15 \mathrm{~T}, 630 \mathrm{~mm}$ bore superconducting magnet using CIC technology and a $30 \mathrm{~T}$ resistive insert. The design of the resistive magnet is being developed. The superconducting magnet consists of two Nb3 $\mathrm{Sn}$ layer wound coils and an outer NbTi coil, probably wound as a set of double layer pancakes. The magnet is cooled by superfluid helium to $1.8 \mathrm{~K}$, is designed for 6000 field cycles, and is designed to withstand without quench a trip of the insert. The user will have easy and unobstructed access to the magnet from the top and bottom, since all the cryogenic infrastructure and the current leads will be housed in a satellite cryostat (see figure 2). Reference is made to pub! ication on the cryogenic system during this conference. This magnet, which will generate a field $33 \%$ higher than the highest field available today, will be operational in 1995 .

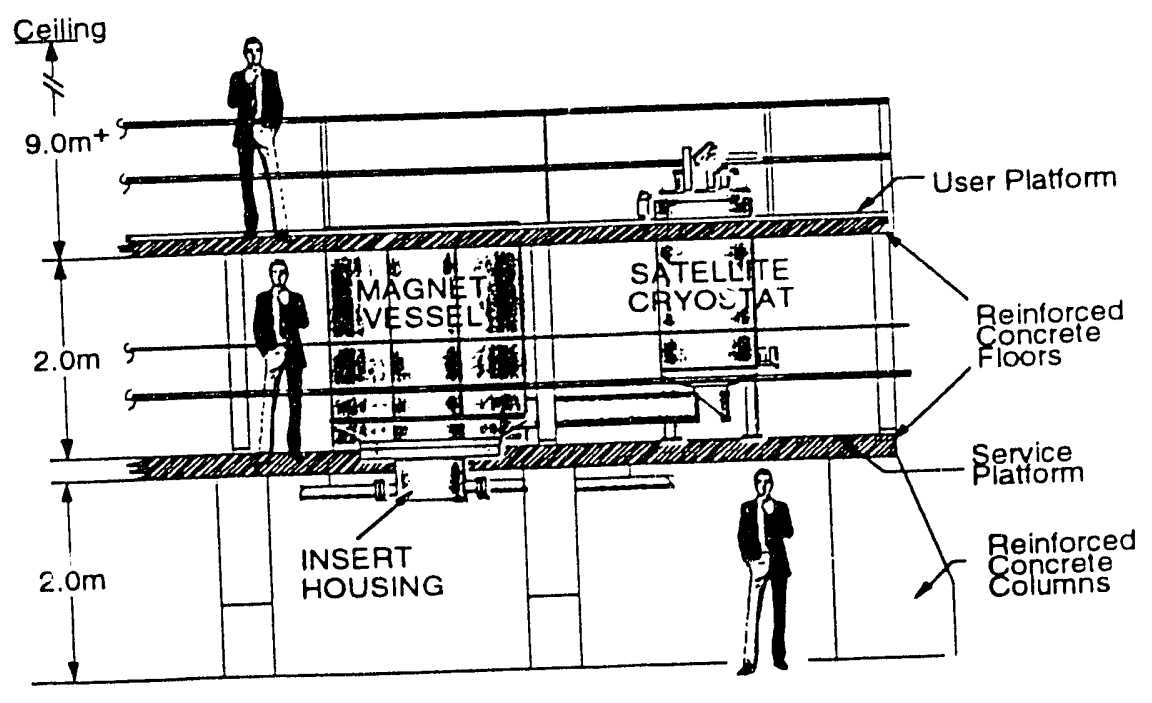

Figure 2. The NHMFL 45T Hybrid Magnet System 
A magnet design program to develop high resolution NMR systems at frequencies greater than $600 \mathrm{MHz}$ has been established. It is the goal of this project to develop a $900 \mathrm{MHz}$ big bore, high homogeneity magnet that will be upgraded to a $25 \mathrm{~T}$ system as soon as suitable conductors are available. To facilitate this task, an additional program has been established to support the development of emerging new superconductors for magnet applications. Investigations to define mechanical, thermal, and electrical stability characterization of the available conductorsand definition of development goals have started. An additional activity covers the field of characterization of more traditional A-15 superconductors in high magnetic fields and also under axial and transverse stress. This work also includes development and characterization of structural materials and composites in the temperature range of $4.2 \mathrm{~K}$ to room temperature. The laboratory will also support a high field NMR imaging program. A $12 \mathrm{~T}$, large warm bore $(400 \mathrm{~mm})$ magnet is under consideration. For the ICR program, a persistent $7 \mathrm{~T}, 4.2$ $\mathrm{K}, 250 \mathrm{~mm}$ warm bore magnet and a $12 \mathrm{~T}, 180 \mathrm{~mm}$ bore magnet are being discussed.

The laboratory will be equipped with a great number of supporting facilities to ease, help, or make possible measurements in the cited magnets, especially at low temperatures. Studies at very low temperatures and very high $\mathrm{B} / \mathrm{T}$ ratios for transport and susceptibility measurements will be a vailable within a few months in cooperation with the NHMFL at the Microkelvin Research Laboratory at the University of Florida in Gainesville. The new system will generate temperatures of $500 \mu \mathrm{K}$, or less, in a field of $20 \mathrm{~T}$ for studies of materials at high magnetic fields and very low temperatures. The demagnetization stage will use a $8 \mathrm{~T}$ magnet. A different system with a slow turn around using a large copper nuclear refrigerant has achieved $45 \mu \mathrm{K}$ and is used for studies of nuclear magnetism in gold and solid helium.

\section{NHMFL IN LOS ALAMOS, NM}

The NHMFL located in Los Alamos, NM operates several pulsed magnet systems. The facility consists of four components, three of which are already available to users. These are:

a) explosive driven flux compression devices that produce $100 \mathrm{~T}$ in a single stage device and up to $220 \mathrm{~T}$ in a double stage device. The pulse length is of the order of $5-10 \mu \mathrm{s}$ and the available magnet bores are 16 and $11 \mathrm{~mm}$, respectively.

b) wire wound pulse coils, driven by the discharge of a $1.1 \mathrm{MJ}, 10 \mathrm{kV}$ capacitor bank, achieve reliably $50-60 \mathrm{~T}$ for $5-10 \mathrm{~ms}$ in bores of 24 and $14 \mathrm{~mm}$ respectively. These magnets have been developed in cooperation with the Catholic University of Leuven, Belgium.

c) a $19.5 \mathrm{~T}$ superconducting magnet with a $52 \mathrm{~mm}$ bore serves as a staging and calibration magnet for the pulsed magnets. It is equipped with a compensation coil to allow for precise temperature measurements and can also be used for independent continuous field experiments. All above magnets have $\mathrm{He}^{4}$ and $\mathrm{He}^{3}$ cryostats giving temperatures from room temperature to 1.5 and $0.5 \mathrm{~K}$ respectively. Dilution refrigerators for $50 \mathrm{mK}$ for the superconducting $20 \mathrm{~T}$ magnet and the $50 \mathrm{~T}$ pulsed magnet will be installed by late 1993 and early 1994, respectively.

d) The fourth component, a $60 \mathrm{~T}$ quasi-continuous magnet with a flat top of at least 100 $\mathrm{ms}$ is in the design stage and is scheduled for installation in 1995. This magnet will be powered by a $1400 \mathrm{MW}$ generator system that has been installed and is operational at LANL. This generator has a stored energy of $600 \mathrm{MJ}$, which can be extracted within one second. Adding a flywheel would increase its capacity to $2000 \mathrm{MJ}$. Engineering of 
the power bus and the power supply units is complete and the procurement process has been started. The requirements for the magnet are, that it should provide a $32 \mathrm{~mm}$ bore at $77 \mathrm{~K}$ with a field homogeneity of $10^{-3}$ or better, and that it should have a cool down time of less than one hour (each cool down requires about $1000 \mathrm{~L}_{\text {of }} \mathrm{LN}_{2}$ after each shot). The construction of the magnet (see figure 3 ) has to be robust and reliable, with a lifetime of 10 years or 10,000 pulses for the outer coils and of 1000 pulses for the inner coils. The magnet will be upgraded, when better conductors with higher strength and conductivities or stronger reinforcement materials become available. The construction chosen is a polycoil design consisting of several mechanically independent and spatially separated coils with external reinforcement shells.

The user facility at NHMFL in Los Alamos opened in December 1992. A wide range of experiments investigating ac and dc magnetization, magneto transport, and phase transitions have been completed through an active user program. These facilities are open to both national and international users through a peer review proposal process.

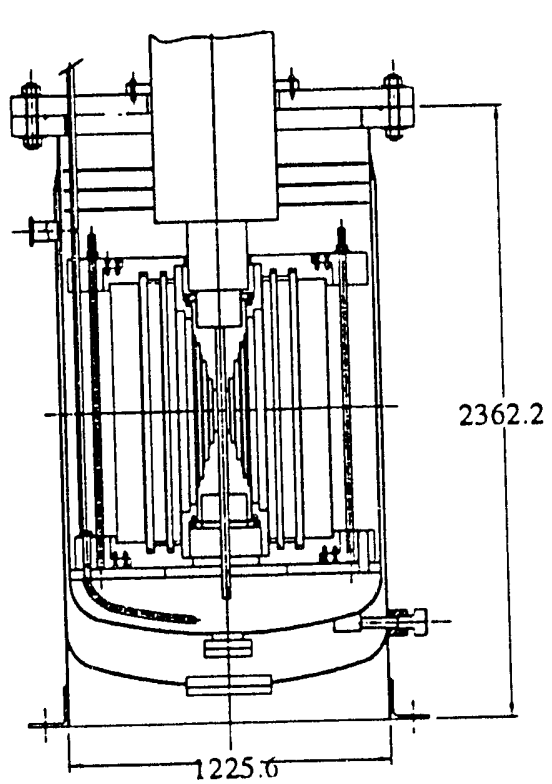

Figure 3. The NHMFL/LANL 60T 100ms Pulse Magnet

\section{GENERAL INFORMATION ABOUT THE NHMFL}

The progress of the laboratory is being jointly funded by the State of Florida and the United States National Science Foundation. The State support provides capital funding for facility construction and permanent equipment support, along with an operating budget to sustain 48 new faculty lines and research positions, 15 technical and administrative positions, and an extensive ( $\$ 1.2 \mathrm{M} /$ year) visitor program. The NSF is providing operating funds for the development and performance of new magnet systems and for the technical support staff.

A strong theory group, headed by Dr. J.R. Schrieffer, was established. A Theory Coordinati-ig Committee was also created to interact with the theoretical condensed matter programs of the participating institutions, and also with the users and visitors of the NHMFL. The in-house research staff and faculty will assist in the development of support facilities necessary 
to respond to the needs of a diverse user community.

Future users of the laboratory held a meeting in Tallahassee on May 20-21, 1993, and completed a list of necessary equipment that would address the needs of the scientific community. This list includes equipment for magneto-optical experiments, infra-red spectroscopy, magneto-optics in the visible, transport measurements, superconducting wire testing, magnetization experiments, state-of-the-art data acquisition, analysis and transfer equipment. It also mentions spectrometers, light sources, sample holders, detectors, lasers, and other more elaborate user amenities. A detailed list is available upon request. The procurement process for the above equipment has been started. A Users' Committee is being installed to advise the NHMFL's Director on important issues dealing with the needs of the user community.

The NHMFL will soon become a full service magnet development and user facility. All areas of research related to magnetic fields will be investigated and supported by this institution. Although, it will not become fully operational until 1995, the NHMFL in Tallahassee will be open in September 1993 with limited user facilities.

\section{ACKNOWLEDGMENTS}

The NHMFL acknowledges support by the State of Florida and the National Sicience Foundation through NSF Cooperative Grant No. DMR 9016241. The authors would also like to thank all the staff members who participated so admirably in this exciting task of establishing a new high magnetic field laboratory. 

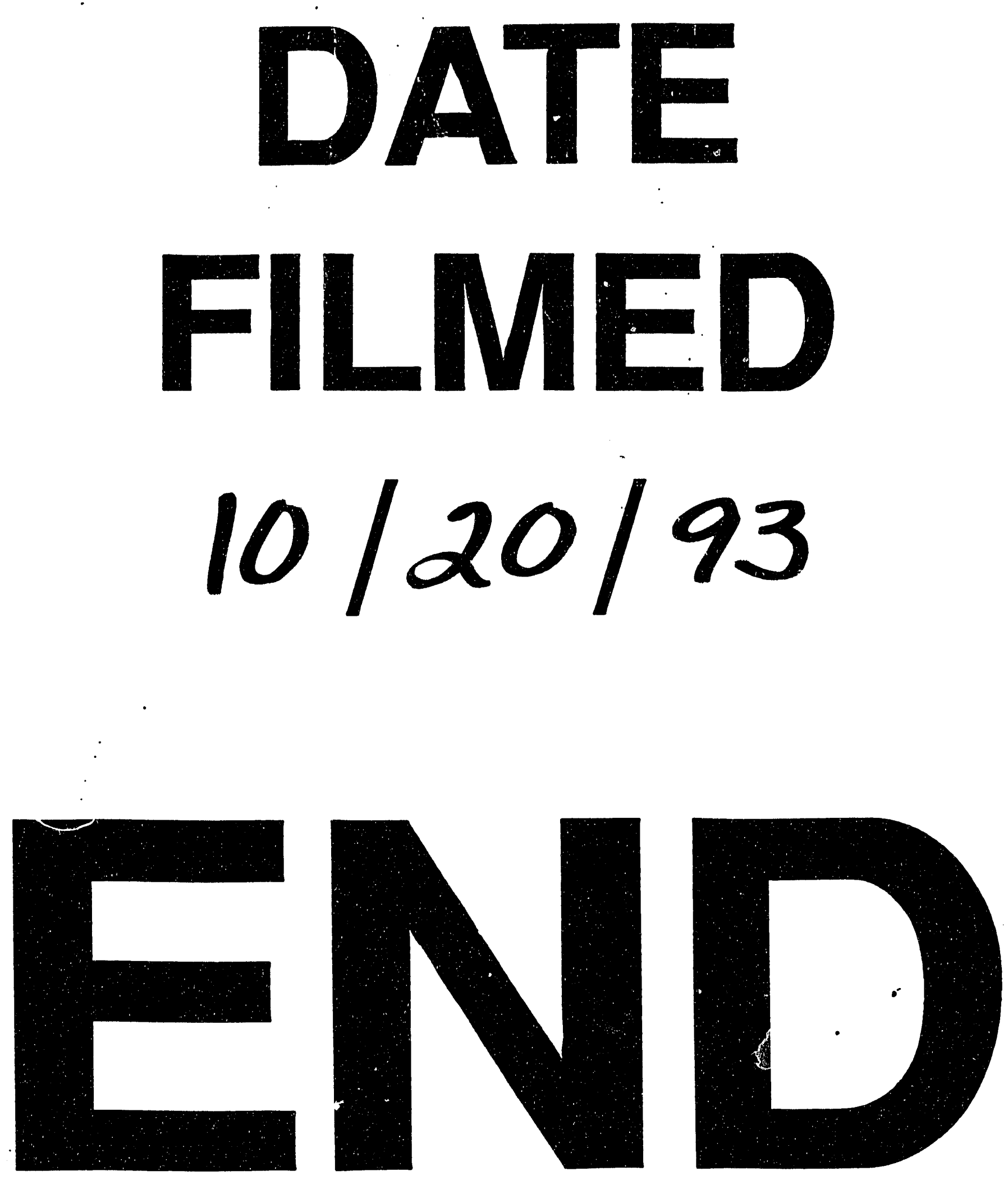